\title{
La alianza chileno-peruana del Tratado de 1929 y la tercería boliviana
}

\author{
The Chilean-Peruvian alliance of the 1929 \\ Treaty and the Bolivian third party
}

\author{
Sebastián Flores Díaz \\ Magíster en Derecho Público \\ Profesor de Derecho en la Universidad UNIACC y en la Escuela de Gobierno de la \\ Universidad de Chile. \\ Doctorando en Derecho, Universidad Autónoma de Madrid. \\ Correo electrónico: sfloresabogado@gmail.com
}

\section{Resumen}

El espíritu del Tratado de Paz y Amistad de 1929 entre Chile y Perú fue una alianza focalizada establecida para sellar una defensa respecto de las pretensiones bolivianas para anexionarse Tacna y Arica. Este espíritu se refleja en la partición de los territorios disputados, así como en el Artículo 3 del Protocolo Complementario, que establece, de forma críptica, que ni Chile ni Perú podrían ceder esos territorios a Bolivia.

La explicación está en los 45 años de conflictos entre Chile y Perú debido a la pretensión boliviana de anexionarse los territorios peruanos que ocupaba Chile tras la Guerra del Pacífico. Sin embargo, tras la cesión de Arica, el fundacional reclamo de Bolivia por anexionarse este puerto se dirigió contra Chile. Tras el Tratado de 1929, la diplomacia boliviana trabajó por romper esta alianza, cuestión que se logró en 1975 con los acuerdos de Charaña.

\footnotetext{
Cómo citar este artículo:

Flores Díaz, S. (2021). La alianza chileno-peruana del Tratado de 1929 y la tercería boliviana. Revista de la Facultad de Derecho y Ciencias Políticas, 51(135), 442-466. doi: https://doi.org/10.18566/rfdcp. v51n135.a07
}

Recibido: 30 de octubre de 2019

Aprobado: 04 de marzo de 2021 


\section{Palabras clave}

Tratado de Paz y Amistad de 1929 entre Chile y Perú; alianza focalizada chilenoperuana; pretensión boliviana sobre Arica; Acuerdos de Charaña.

\section{Abstract}

The spirit of the 1929 Peace and Friendship Treaty between Chile and Peru was a focused alliance established to seal a defense against Bolivian claims to annex Tacna and Arica. This spirit is reflected in the division of the disputed territories, as well as in Article 3 of the Complementary Protocol, which establishes, in a cryptic way, that neither Chile nor Peru could cede those territories to Bolivia.

The explanation lies in the 45 years of conflicts between Chile and Peru due to the Bolivian claim to annex the Peruvian territories occupied by Chile after the War of the Pacific. However, after the cession of Arica, Bolivia's founding claim to annex this port was directed against Chile. After the 1929 Treaty, Bolivian diplomacy worked to break this alliance, which was eventually achieved in 1975 with the Charaña agreements.

\section{Keywords}

Treaty of Peace and Friendship of 1929 between Chile and Peru; Chilean-Peruvian focused alliance; Bolivian claim on Arica; Charaña Agreements.

\section{Introducción}

El 1 de octubre de 2018, la Corte Internacional de Justicia de La Haya (La Corte, la CIJ o La Haya) entregó su decisión sobre el diferendo entre Bolivia y Chile en la que rechazó las pretensiones bolivianas. En el fallo se menciona seis veces el Tratado de Paz y Amistad entre Chile y Perú de junio de 1929, un buen instrumento para la amistad chileno-peruana, pero que obstruyó de forma significativa las pretensiones bolivianas por obtener una salida al mar durante el siglo XX.

El presidente peruano, Augusto Leguía, indicó en el año de suscripción del Tratado que este era "el hecho capital entre los muchos hechos notables que en diez años ha realizado mi Gobierno” (s.f., p. 1). Leguía asumió que era mejor entregar Arica a Chile y, de este modo, asegurar una buena relación bilateral (Ríos, 1959, pp. 236-237). El diplomático peruano, Alberto Ulloa (reconocido 
opositor a Leguía) expresó que el Tratado fue un arreglo útil y conveniente para la política internacional del Perú (1941, p. 241), y tal vez, la gestión más importante de Leguía. Fue un punto de inflexión en la relación entre Chile, Perú y Bolivia (González, 2008).

El Tratado de 1929 determinó un vínculo cultural, económico y diplomático (Wagner, 1961), entre Chile y Perú. Alberto Ulloa (1987) señala que la premisa de este acuerdo fue la exclusión de Bolivia en la relaciones chileno-peruanas, y para ello Perú no buscaría una alianza con Bolivia en contra de Chile, situación que conlleva la constante oposición chilena, y Chile tampoco gestionaría la alianza con Bolivia en contra del Perú, como ocurrió desde el final de la Guerra del Pacífico hasta la década de 1920, cuando Chile ofrecía le ofrecía a Bolivia las provincias de Tacna y Arica, como acceso al mar, a pesar de que, jurídicamente, pertenecían al Perú.

Leguía fue derrocado al poco tiempo de este discurso, y su sucesor, el teniente coronel Luis Miguel Sánchez Cerro, desconoció el tratado de paz que aquel celebró con Colombia; sin embargo, respetó el tratado con Chile. Lagos consigna que Sánchez Cerro aseveró que la amistad con Chile está sellada y "lo pactado [...] es compromiso de honor. Sobre esto no hay nada que hablar” (1981, p. 87).

A pesar de que el tratado contemplaba que Arica quedara en manos chilenas, para el Perú esta alternativa era satisfactoria, pues sellaba una alianza con su antiguo enemigo. Zapata (2014) indica que esta alternativa fue bautizada “opción de paz”, por el historiador peruano José de la Riva-Agüero, que contenía como estipulación implícita que Bolivia era un tercero ajeno al acuerdo, y que cualquier acuerdo entre esta y Chile o Perú sería percibido como una amenaza para la seguridad propia.

Esta alianza es el elemento que ha cerrado el paso a la histórica demanda boliviana por anexionarse Arica, complicando las relaciones con Chile y también con Perú.

Esta investigación se realizó en el contexto de las demandas internacionales de Perú y Bolivia en contra de Chile, en las que ambos países reclamaban derechos sobre el océano Pacífico. Ambas pretensiones estaban políticamente vinculadas, a pesar de que los argumentos jurídicos utilizados fueron diferentes. 
Al respecto, la coagente peruana, Marisol Agüero señaló que “cualquier posible solución a la mediterraneidad boliviana se vincula estrechamente al tema de la delimitación marítima peruano-chilena” (2001, p. 239)¹.

El presente trabajo se divide en cuatro partes. En primer lugar, se abordará el espíritu del Tratado de 1929 a la luz de sus contemporáneos, para examinar los reclamos históricos de Bolivia para anexionarse Arica, en la segunda parte. En el tercer apartado se revisará la política boliviana posterior al Tratado de 1929 y la cesión de Arica a Chile, cuando este se convirtió en el subrogante legal del Perú en la pretensión boliviana. En el cuarto acápite se analizarán las negociaciones de Charaña, el principal argumento de la demanda boliviana hacia Chile, que, de acuerdo con este trabajo, constituye una herida letal al espíritu del Tratado de 1929.

\section{El espíritu del Tratado de Paz y Amistad de 1929}

Muñoz Machado (2017) explica que el espíritu de las normas jurídicas es el criterio normativo que atiende a la finalidad del que inspiró su adopción. Sin lugar a dudas, el principal fin del Tratado de 1929 era solucionar la cuestión de Tacna y Arica, que jurídicamente pertenecían a la soberanía peruana, pero eran ocupadas por Chile. Sobre eventuales incumplimientos del Tratado de Ancón de 1884, que cedió la soberanía de Iquique a Chile y permitió la ocupación chilena de las mencionadas provincias, ni las historiografías y diplomacias peruana ni chilena tienen una posición común. Desde ambos lados se defiende la respectiva posición nacional, cuestión que no pareciera ser cuestionable ex ante. Sin embargo, parte íntegra del Tratado de 1929 es el protocolo complementario que se comenta a continuación, y que constituye una interpretación posible del Tratado en su conjunto.

Bákula (2002) indica que la interpretación del Tratado de 1929 está íntimamente ligada a la conflictiva historia de las relaciones peruanas y chilenas con Bolivia. Zapata (2014) explica que los conceptos esenciales de la diplomacia peruana, al momento de las negociaciones con Chile, eran que esta deberá ser mediterránea, y que Chile no debería alentar o atender los reclamos bolivianos, y menos a costa de enemistar al Perú con Bolivia. Para

\footnotetext{
1 En una extraña declaración a medios bolivianos, en 2009, el entonces presidente Evo Morales señaló que la demanda peruana contra Chile se hizo "para que Bolivia no tenga salida al mar" (El Universo, 2009). Si bien es cierto que ambas pretensiones políticamente (y no jurídicamente) están vinculadas, estadistas, diplomáticos y expertos peruanos desmintieron esta declaración.
} 
estos efectos, se estipuló la cláusula 1. a del Protocolo complementario al Tratado de 1929, que señala:

Los Gobiernos del Perú y de Chile no podrán, sin previo acuerdo entre ellos, ceder a una tercera potencia la totalidad o parte de los territorios que, en conformidad al Tratado de esta misma fecha, quedan bajo sus respectivas soberanías, ni podrán, sin ese requisito, construir, a través de ellos, nuevas líneas férreas internacionales

Esta cláusula se consideró en Chile como "la válvula de seguridad de la paz con el Perú” (Ríos, 1959, p. 229), pues tenía una finalidad defensiva respecto de Bolivia. Alberto Ulloa (1941) concordó con esta interpretación al indicar que la

estipulación está hecha para dar al Perú un derecho de veto en el caso de que Chile haga la cesión a Bolivia, cautelándose de esta manera [...] los intereses políticos y económicos futuros de nuestro país. Al mismo tiempo, en el caso que la lógica hace absurdo, pero que el sentimiento público ha admitido como verosímil, de que Bolivia agrediera al Perú y en el caso bien poco probable que lo venciera por circunstancias extraordinarias, cualquier imposición victoriosa por la fuerza para solucionar territorialmente un problema portuario exigiría para funcionar el consentimiento chileno $\mathrm{y}$, cabiendo la esperanza que pudiera negarlo, por estimarlo contrario a sus intereses, Bolivia se vería obligada, para realizarlo, imponerlo también a Chile. (p. 283)

Ulloa (1941) señala que el espíritu del pacto fue establecer una solidaridad chileno-peruana frente a los reclamos bolivianos, como una cláusula de reciprocidad. Con el Tratado, Chile puso fin a su política oscilante respecto a la aspiración marítima de Bolivia, y en conjunto con el Perú intentaron dar un golpe mortal a la reivindicación ariqueña de Bolivia (Bernal, 1938).

Para determinar el espíritu de un tratado internacional es necesario conocer la intención de las partes contratantes (Parry, 2008), que es una de las mejores guías de interpretación (Brownlie, 2012), o como señala Martens (s.f.), "los mejores intérpretes son los mismos firmantes” (p. 533). El citado artículo 1. del Protocolo complementario es el que mejor identificaría la intención de los negociadores de este Tratado, que, de acuerdo con el negociador chileno, el canciller Conrado Ríos, tuvo por objeto excluir expresamente a Bolivia de los asuntos chileno-peruanos (1959). Esta afirmación se confirma con el artículo 
2. del Protocolo, que mejoró los derechos del Perú en Arica en comparación a los que el Tratado de Paz y Amistad de 1904 entre Chile y Bolivia otorgó a La Paz (Fernández, 2004). Algunos explican que Perú mantuvo una "soberanía residual” sobre Arica.

Andrés Bello explica, que es necesario atender al pensamiento de la persona que dictó la cláusula para interpretarla (1864). El canciller Ríos reconoció ser el autor de la cláusula, señalando que la frase "sin acuerdo previo entre ellos" tenía por objeto

cerrar el paso a las futuras reclamaciones bolivianas de salida al mar por Arica. Si se amplió la exigencia del acuerdo previo para disponer de Tacna, fue en procura de una apariencia de obligación equilibrada, ya que, bien se sabe, Bolivia no perdió su salida al mar a manos peruanas, y su relación histórica fue siempre con Arica y no con Tacna. (Citado en Pinochet de la Barra, 1987, p. 45)

Durante las negociaciones del Tratado de 1929, Ríos instruyó al embajador Emiliano Figueroa Larraín, en el pensamiento de que era necesario "cerrar a Bolivia todos los caminos por los cuales pueda continuar con su vieja diplomacia de dividir a Chile y el Perú”, por lo que había que impedir una posibilidad de la cesión de Arica en el futuro (Fernández, 2004, p. 594). El 16 de abril de 1929, Figueroa presentó la estipulación al presidente Leguía, quien la recibió con satisfacción, pues, en reiteradas ocasiones, manifestó que no aceptaría la presencia boliviana en Tacna y Arica. Leguía declaró que Chile y Perú tenían un frente único frente a Bolivia, y que Perú y Bolivia serían uno desde el momento de la aprobación del Tratado (Fernández, 2004, pp 592-594). Con la anexión de Arica, Chile subrogó a Perú respecto de la histórica pretensión boliviana.

Para frenar potenciales presiones bolivianas, Perú celebró con Bolivia el Pacto de Amistad y No Agresión de 1936 (Bákula, 2007), cuyo artículo 1. consigna que "Bolivia no tiene ningún problema político ni territorial pendiente con el Perú”. El corolario de esta cláusula es que cualquier reclamo boliviano solo podría dirigirse contra Chile y por Arica, hipótesis que el Perú puede detener por su "derecho de veto" que consigna el artículo 1 . $^{\circ}$ del Protocolo Complementario (Ulloa, 1941, pp. 283-284).

Además, el fuerte sentimiento nacionalista en Tacna y en Arica, respectivamente, junto al consentimiento previo del Perú, constituyeron una barrera insalvable para que La Paz pudiera conseguir un acceso al mar 
(Espinosa, 1965).

Bolivia intentó sortear este escollo reinterpretando el artículo $1 .^{\circ}$ del Protocolo Complementario como un procedimiento. Según esta interpretación, La Paz debería negociar, primero, con Chile, y luego, solicitar a Perú su autorización para salir soberanamente al mar por Arica. Con esto nació un problema insalvable: el reclamo boliviano por Arica es bilateral, pues La Paz lo dirige a Chile, con naturaleza y solución trilateral (Andaluz, 2002).

\section{La pretensión boliviana sobre Arica}

En los reclamos bolivianos por un puerto, contextualizados en el siglo $\mathrm{XX}, \mathrm{y}$ en los relativos a un acceso soberano al mar, sucedidos en el siglo XXI, subyace la histórica pretensión boliviana sobre Arica, desde su fundación en 1825 (Andaluz, 2002). Esta ciudad fue el puerto principal utilizado por el Alto Perú durante la época colonial (Mercado, 1988), pero nunca dependió administrativamente de la Audiencia de Charcas (la antecesora de la actual Bolivia).

Alberto Ulloa (1941) planteó, al respecto, que

la comunicación oceánica de Bolivia no es una cuestión surgida como consecuencia de la Guerra del Pacífico y de la pérdida del litoral boliviano por la conquista chilena, sino anterior a estos hechos históricos, porque el litoral de Atacama no satisfacía sino en parte las necesidades de comunicación. (p. 269)

Esta opinión es compartida por peruanos y bolivianos. Desde Perú, Denegri (1988) señala que, desde el nacimiento de Bolivia, la relación con Perú tuvo como eje la pretensión boliviana sobre Arica, agregando que la élite boliviana fundamentó esta pretensión con base en su "mediterraneidad”. Desde Bolivia, Siles (2012) explica este reclamo, señalando que "Arica fue considerada como la llave de las provincias del Alto Perú [...] 'la puerta natural hacia el mar’”. (p. 43)

\section{La discusión sobre la dependencia colonial de Arica}

Este asunto se remonta a 1784, cuando Arica dependía de la intendencia de Arequipa (González, 2006), mientras que Charcas dependía del Virreinato del Río de la Plata. A pesar de ello, la historiografía boliviana (así como sus diplomáticos y juristas) fundan sus derechos en el océano Pacífico desde la 
época colonial, cuestión que no es tan clara, pues las jurisdicciones coloniales se superponían. Tampoco es coherente que la Audiencia de Charcas, dependiente de Buenos Aires, haya cortado en dos el territorio del Virreinato del Perú (véase el Mapa N. ${ }^{\circ}$, tomado de El libro del mar, elaborado en 1894).

Figura 1. Territorios de la Audiencia de Charcas según Bolivia

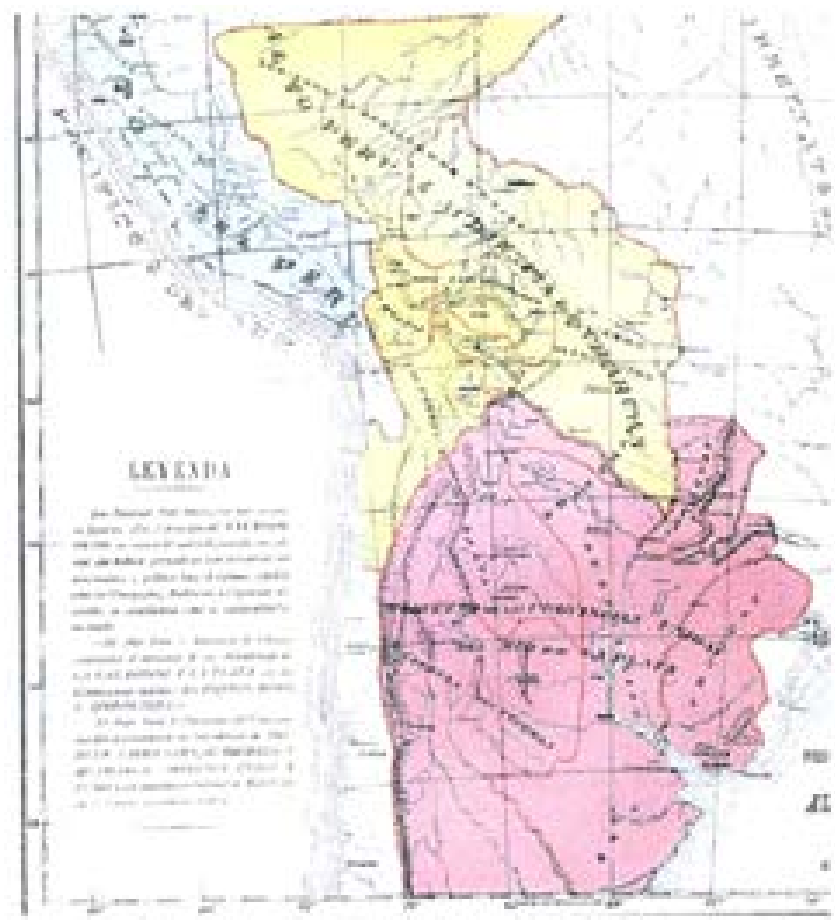

Fuente: Estado Plurinacional de Bolivia, 2014, p. 25.

Esta versión es controvertida en Perú por el historiador y diplomático, Raúl Porras (1930), quien indica que la Audiencia de Charcas no tuvo litoral, pues la provincia de Atacama no dependía de Buenos Aires sino del Perú. Añade, además, que

la Audiencia de Lima limitaba según la cédula de su erección [...] con el reino de Chile, pero cuando se constituyó Bolivia, el general Sucre se apoderó 
de una parte del litoral desierto de Atacama, para darle costa y puerto a Bolivia. (p. 22)

En su libro de 1930, Porras publicó un mapa de colonial que reafirma su posición (véase figura N. ${ }^{\circ}$ ), en el que Atacama queda bajo la jurisdicción del Perú.

Figura 2. Límites coloniales según Porras

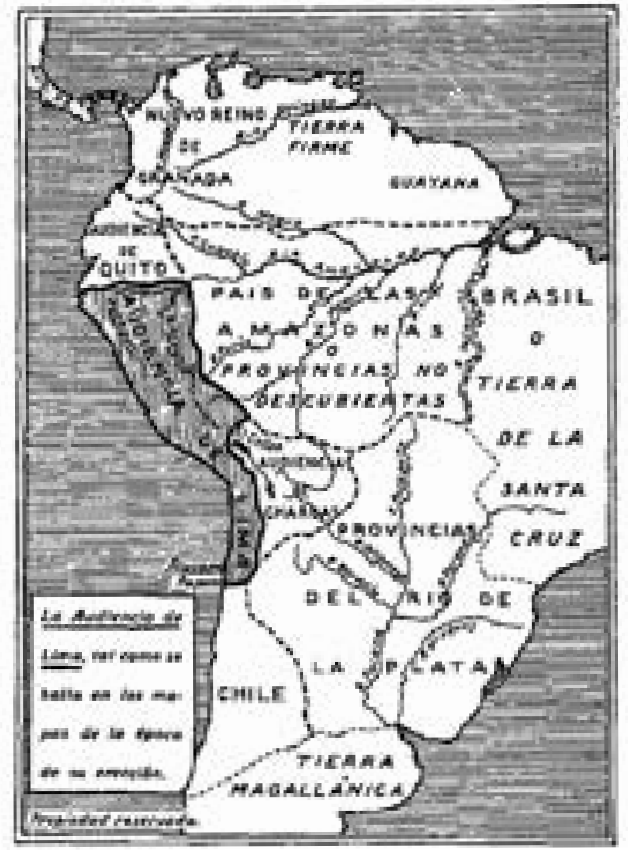

Fuente: Porras, 1930.

El jurista boliviano Horacio Andaluz (2002) sostiene que los documentos coloniales no son precisos, por lo que no sirven para fundamentar la pretensión boliviana, y que el principio del uti possidetis iure juega en contra de los intereses de su país, pues los documentos coloniales dan más argumentos para demostrar que la República de Bolívar nació mediterránea. Porras (1930) sostiene que, de acuerdo con el Uti Possidetis de 1810, Chile y Perú eran vecinos, 
por lo tanto, la Audiencia de Charcas no estaba entremedio (1930). Algunos trabajos tratan de acudir a la historia para defender la posición boliviana, sin embargo, no citan más fuentes que la información oficial del gobierno boliviano (véase Velázquez, 2007).

\section{El reclamo de la "República de Bolívar"}

Al momento de la fundación de la República de Bolívar, en 1825, se le asignó la zona entre el Río Loa y el Río Paposo como litoral (Porras, 1930). En ese momento la élite altoperuana reclamó que la corona española les había asignado Arica como puerto y parte de su territorio (Escobari, 1979). La paradoja de los actuales reclamos bolivianos está en que, por un lado, se reclama el litoral de Atacama, para argumentar que nació como república con costa en Antofagasta y, por otro, se sostiene que Arica le pertenecía desde la colonia.

La distancia de Arica con el centro boliviano era menor que con la costa que otorgó Simón Bolívar (Andaluz, 2002). Esta circunstancia provocó el debate entre anexar Arica o habilitar otro puerto en el territorio asignado por Bolívar. Cobija apareció como una solución provisional, mientras se realizaban las gestiones para la anexión ariqueña, para evitar conflictos con el Perú (Téllez, 1989). Este puerto no tuvo el auge esperado, por la distancia, el desierto, la falta de agua dulce para las bestias y la falta de caminos que imposibilitaron su consolidación (Denegri, 1989).

El gobierno boliviano le encomendó al general O’Connor inspeccionar el litoral del Pacífico y determinar el mejor lugar para instalar un puerto para Bolivia. Tras su expedición, quedó con una pésima impresión de los puertos de Atacama, Cobija, Mejillones y el Loa (Basadre, 2014). Por ello, Antonio José de Sucre, presidente provisorio de Bolivia, le pidió a Bolívar, en una carta de 27 de enero de 1826, que: "Sería bueno que UD. mostrase algo al Congreso peruano de la pretensión de esta República para que se le ceda Arica mostrando que Arica es un puerto que sólo da introducciones á Bolivia” (transcrita en O'Leary,1879, pp. 291-292). En sus cartas del 28 de febrero, 12 de abril, y de 11 de mayo insiste sobre este punto, indicando que la "adquisición de Arica para esta República es de lo más importante, de que ella puede tratar. Arica será un puerto magnífico para Bolivia”, añadiendo que para Perú no significa nada (O'Leary, 1879, p. 319). Insistió, en su carta del 4 de agosto, haciendo presente que Arica quería ser anexada a Bolivia (O’Leary, 1879, p. 367). El cabildo de Tacna había comunicado su decisión de ser parte de Bolivia el 30 de enero de ese año. El 2 de febrero, el cabildo de Arica realizó un pronunciamiento similar (Varas, 1922). 
El 15 de noviembre de 1826, Perú y Bolivia suscriben los tratados de Chuquisaca, dos acuerdos sobre federación y canje territorial. El canje consideraba que Perú cediera toda la costa desde los paralelos 18 a 21; Bolivia, todo el norte hasta el río Beni, y una compensación de 5 millones de pesos (Ríos, 1963). La oposición del Consejo de Gobierno peruano y del mariscal Santa Cruz (en ese entonces presidente de esta instancia) impidieron que estos tratados entraran en vigor (Novak \& Namihas, 2013). Santa Cruz señaló, que aceptar la cesión sería un abuso de la confianza que Perú depositó en él (Basadre, 2014). A inicios de 1836, Arica, Moquegua, Tacna y Lucumba organizaron cabildos con la intención de anexarse a Bolivia. El 22 de marzo, el cabildo de Arica declaraba que "se une a la Nación Boliviana y forma porción de su familia”. El mariscal Andrés de Santa Cruz, para evitar problemas con el Perú, se opuso a esa petición y transformó a Arica en el puerto principal del Estado Sud-Peruano (Varas, 1922).

El 9 de diciembre de 1841, luego de un conflicto bélico, los bolivianos ocuparon Arica, Moquegua y Tarapacá, y pretendían negociar su retirada de esas zonas, a cambio de la cesión de Arica. Chile buscó mantener el statu quo, pues el triunfo boliviano podría implicar un renacimiento de la Confederación Peruano-Boliviana, y presionó por un acuerdo que dejara esas ciudades en manos peruanas (Novak \& Namihas, 2013).

Un año antes de la guerra del Pacífico, el Concejo Departamental de Tacna manifestó su situación de abandono por parte del gobierno central del Perú. En una comunicación de 18 de marzo de 1878, solicitó una unión aduanera con Bolivia (Varas, 1922).

\section{El reclamo entre la guerra del Pacífico y el Tratado de 1904}

Tras la guerra del Pacífico, Bolivia aceptó la tregua propuesta por Chile, pues quedaba la expectativa de obtener, como compensación territorial, la cesión de Tacna y Arica, ahora ocupadas por Chile (Siles, 2012). El éxito de esta solución estaba supeditada a los resultados del plebiscito estipulado en el Tratado de Ancón (Andaluz, 2002). Esto se conoció como la "política boliviana" que realizó Chile, una alianza con La Paz en contra de los intereses peruanos. Si Chile ganaba el plebiscito, cedería Tacna y Arica a Bolivia, cuestión que se refleja en los derechos especiales que el Pacto de Tregua de 1884 reconocía un régimen especial para Bolivia en Arica (Eckholt, 2012). Los artículos 5. y 6. ${ }^{\circ}$ de este instrumento reconocen el rol del puerto de Arica para las importaciones a Bolivia. Incluso consagra que el $75 \%$ de los aranceles que 
se cobren se destinarán a Bolivia para el pago de una deuda con Chile, y una vez que dicha obligación fuera pagada, Chile dejaría de cobrar tributos para establecer un régimen de libre tránsito en Arica.

En 1895, Bolivia y Chile firmaron tres tratados: uno de paz, otro de cesión territorial y otro de comercio. En virtud del primero se reconocía la soberanía chilena sobre territorio que quedó en su posesión luego del tratado de tregua. El segundo, y más importante, prescribía en su artículo 1. que:

si a consecuencia del plebiscito que haya de tener lugar, en conformidad al Tratado de Ancón, o a virtud de arreglos directos, adquiriese la República de Chile dominio y soberanía permanente sobre los territorios de Tacna y Arica, se obliga a transferirlos a la República de Bolivia.

En caso contrario, Chile quedaba obligado en virtud del artículo 4 . $^{\circ}$ a: "ceder a Bolivia la caleta Vítor hasta la quebrada de Camarones u otra análoga [...]”. En Chile se exigió que los tres tratados fuesen aprobados para entrar en vigencia, pero Bolivia rechazó el tratado de comercio. Por esta razón, Chile desestimó los tres acuerdos.

La reacción peruana a este tratado fue manifestar que no se renunciaría a recuperar Tacna y Arica, provincias que no serían cedidas ni a Chile ni a Bolivia (Ríos, 1963).

La pugna interna boliviana entre conservadores y liberales impidió el acuerdo en 1895, pues los liberales boicotearon las gestiones realizadas por los conservadores en 1895. Bolivia cedió la Puna de Atacama a Argentina, sin considerar que Chile consideraba que el territorio era propio, lo que alejó la posibilidad de otro acercamiento (Guzmán, 2015). La transacción pretendía asegurar la soberanía boliviana en Tarija, que también era reclamada por Argentina.

En 1904 se celebró el Tratado de Paz entre Bolivia y Chile. Ahora estaban en el poder los liberales, y priorizaron el acceso a un puerto para las exportaciones de estaño, más que la soberanía en el litoral. La producción minera boliviana requería con urgencia líneas ferroviarias para llevar el mineral a los puertos. Chile ofrecía eso a cambio de la cesión. Los grandes mineros, como Patiño, Aramayo y Hoschild facilitaron este acuerdo (González, 2008).

El problema real de Bolivia no era la ocupación chilena del litoral, sino la falta de caminos, que unido a los derechos aduaneros que se cobraba en 
los puertos de Antofagasta y Arica restringían las ganancias de los grupos mineros (Guzmán, 2015). Los derechos se usaban para pagar el empréstito de 1867 con Chile. Por esta razón, los liberales apostaron por un acuerdo que liquidara la obligación contraída en 1867 y permitiera un régimen de libre tránsito en los puertos controlados por Chile, en lugar de intentar recuperar el litoral perdido. Brockman (2014) afirma que: "El grueso de los bolivianos reniega de los protagonistas y de las circunstancias que llevaron a la firma del Tratado de 1904”. (p. 81)

\section{El Tratado de 1904}

El Tratado de 1904 es un instrumento paradójico para los intereses bolivianos, pues consagró jurídicamente la cesión territorial de Antofagasta, pero dio derechos a Bolivia en Arica. Andaluz (2002) señala que esta pretensión no es un conflicto jurídico, "sino únicamente de intereses. [...] jurídicamente a Bolivia no le asiste ningún derecho sobre las costas del Pacífico” (p. 19). Los bolivianos argumentan que, en 1904, al ceder Antofagasta, Chile habría ofrecido una zona marítima propia. Siles (2012) afirma, en este sentido, que no es "en el terreno jurídico donde se sitúa el debate sino en el de la razón, la equidad y la justicia internacionales” (p. 58).

La paradoja del Tratado de 1904 yace en los derechos de libre tránsito, el ferrocarril, y otros elementos materiales que acrecentarían la presencia boliviana en Arica, pero que se cuestiona por la pérdida del litoral. Fernández (2014) señala que

el Tratado de 1904 suscrito cuando todavía no había concretado la posesión del dominio de esos territorios, vinculó físicamente a La Paz con Arica a través del ferrocarril, cuya construcción Chile asumió a cambio del Departamento del Litoral (p. 64).

El Tratado de 1904, que dio títulos jurídicos sobre Arica, configuró la conciencia boliviana de la pérdida del litoral (González, 2006). Daniel Salamanca justificó esta decisión señalando que "perder Arica sería como perder la llave de todos los tesoros de Bolivia, que Chile tiene por suyos” (citado en Escobari, 1979, p. 261).

En 1910, el canciller boliviano, Daniel Sánchez Bustamante, solicitó a Perú y Chile que cedieran Tacna y Arica a Bolivia, pues, en su opinión, habría un vínculo efectivo por la dependencia geográfica y comercial con Bolivia, mientras que para Chile y Perú solo habría un asunto de dignidad nacional de por medio. 
En 1919, el expresidente de Bolivia, Ismael Montes (en cuyo primer gobierno se suscribió el Tratado de 1904), escribió a las cancillerías de Francia e Inglaterra, argumentando que su país tenía derechos superiores que Perú sobre Tacna y Arica. También, hizo una presentación a la Sociedad de las Naciones, en la que expresó que la paz latinoamericana dependía de la cesión de Arica a Bolivia (Escobari, 1979). Por ello, en virtud del artículo 19 del Tratado de Versalles, era necesario que la Liga invitara a Chile y a Bolivia a revisar el Tratado de 1904 (Guzmán, 2015).

En 1920, Chile y Bolivia suscribieron un acta protocolizada, en la que acordaron que Chile entregaría una salida al mar al norte de Arica. Por su parte, La Paz se comprometió a colaborar en que Tacna y Arica quedaran en manos chilenas (Denegri, 1988). El canciller boliviano de la época, Carlos Gutiérrez, señaló que la incorporación de estas provincias a Bolivia procedía por "una tradición que en justicia debe considerarse como un derecho que ella adquirió a esos territorios" (citado en Bustos, 2004, pp. 138-139), a lo que el canciller peruano, Melitón Porras, les recordó que la intromisión boliviana no aumenta ni disminuye los derechos del Perú sobre Tacna y Arica, y que su país no cedería sus derechos en Tacna y Arica a Bolivia.

Esta gestión fracasó por la negativa peruana, y por un golpe de Estado en Bolivia. El presidente liberal Gutiérrez Guerra fue depuesto, y la junta de gobierno que tomó el poder y lo reemplazó era "recuperacionista" (concepto con el que se define en Bolivia a quienes defienden la recuperación del litoral perdido en lugar de pedir una salida al mar por Arica). Los nuevos gobernantes bolivianos querían la recuperación del litoral perdido, la revisión del Tratado de 1904 y el respeto de los derechos del Perú sobre Tacna y Arica. Los liberales defenestrados siguieron planteando el acceso soberano al mar por Arica (Guzmán, 2015).

Bolivia intentó ser considerada como un actor en las negociaciones por Tacna y Arica durante la década de 1920. En un primer momento, durante el arbitraje que dirigían los Estados Unidos, el Secretario de Estado Charles Hughes señaló que la inclusión de La Paz en este proceso solo concernía a los gobiernos de Perú y Chile, desconociendo “tercería boliviana” (González, 2006). Su sucesor, Frank Billings Kellogg, propuso que Chile y Perú se comprometieran libre y voluntariamente a ceder a Bolivia a perpetuidad todo derecho, título o intereses que tengan en Tacna y Arica (González, 2008), propuesta que fue rechazada. 
En plena negociación del Tratado de 1929, se contempló la posibilidad de una administración trinacional de Arica o su cesión a Bolivia (González, 2008). La opción peruana fue la exclusión boliviana del asunto.

\section{La política boliviana post Tratado de 1929}

Tras la ratificación del Tratado de 1929, la cancillería boliviana protestó y manifestó su reserva (González, 2008), pues consideró que el protocolo fue “directamente pactado contra Bolivia”. En esta queja se evidencia que Bolivia quería ser parte del acuerdo, pues entendía que su salida al mar por Arica era un tema trilateral, pero que Perú y Chile le cerraron el camino (Brockman, 2014). Desde entonces oscila entre el acercamiento directo con Chile y una campaña multilateral para revisar el Tratado de 1904 (Correa \& García, 2016). Sin embargo, estas acciones omiten el alto rechazo que genera en la población chilena cualquier cesión territorial (Lacoste \& Jiménez Cabrera, 2016) y que la campaña internacional en contra de Chile indispone más a la opinión pública chilena.

Bolivia no insistió en el asunto, porque se enfrentó a la Guerra del Chaco, y necesitaba la aquiescencia de Chile y Perú para importar material bélico a su territorio (Denegri, 1989).

Tras 14 años, Bolivia instaló la idea de "un puerto para Bolivia”, aceptando el Tratado de 1929, pero interpretando el artículo $1 .^{\circ}$ del Protocolo Complementario como un procedimiento para una negociación directa con Chile, para posteriormente solicitar la anuencia del Perú. De este modo, Bolivia desnaturalizó el Pacto de 1929, relegando a segundo plano a Perú, obviando su "soberanía residual” sobre Arica. Esta hermenéutica boliviana no dimensionó que Arica es para Perú la "provincia cautiva”, cuya cesión es una cuestión de honor nacional. En efecto, Perú prefiere que Arica siga bajo soberanía chilena en lugar de ser cedida a Bolivia. La cuestión central sigue siendo la guerra del Pacífico, en la cual Perú se involucró para defender a su aliada Bolivia, y esta dejó la guerra tras un año de combates. Hasta la actualidad en Bolivia se cree que Perú apoyaría una eventual solución al norte de Arica (Guzmán, 2015).

La demanda boliviana reapareció en la agenda internacional en 1943, cuando se realizaron gestiones diplomáticas en Estados Unidos y en Santiago, sin éxito (Orias, 2004). En 1945, La Paz volvió a plantear la necesidad de revisar el Tratado de 1904, en la inauguración de la Organización de las Naciones Unidas. 
En noviembre de 1946, en las ceremonias de la asunción del mando del presidente chileno, Gabriel González Videla, el canciller boliviano, Aniceto Solares, le planteó el problema al mandatario chileno. Hubo conversaciones informales, en las que trataron dos alternativas para no afectar la continuidad territorial: un enclave o un corredor al norte de Arica. El enclave nunca fue muy estudiado.

González Videla mantuvo conversaciones con Alberto Ostria, embajador de La Paz en Chile. Según Ostria (1998), el presidente chileno habría propuesto una franja territorial de cinco kilómetros de ancho al norte de Bolivia, un desvío del ferrocarril Arica-La Paz hacia ese nuevo puerto y el traspaso de la sección chilena del ferrocarril a Bolivia. Chile recibiría una compensación que implicaba el aprovechamiento de las aguas del Titicaca (Pinochet de la Barra, 1987). Harry Truman, presidente de los Estados Unidos, impulsó estas conversaciones.

Hubo un intercambio de notas diplomáticas en junio de 1950, entre los cancilleres Alberto Ostria, de Bolivia, y Horacio Walker, de Chile. Estas eran una invitación al diálogo más que trabajos previos para la celebración de un acuerdo (Cortés, 2015). Ostria envió su nota el 1 de junio, y se filtró al público. La prensa argentina informó la existencia de una negociación para ceder territorios al norte de Arica a Bolivia. El día 6 del mismo mes, el diario El Mercurio de Chile comunicó que había negociaciones chileno-bolivianas (Guzmán, 2015). El 11 de junio, la revista chilena Ercilla publicó un reportaje sobre la negociación, señalando que se contemplaba la cesión de un corredor a 32 km al norte de Arica, y como compensación, Bolivia daría aguas del Titicaca para riego y energía hidroeléctrica. Al día siguiente, el Ministerio de Relaciones Exteriores de Chile precisó que no existía una negociación de ese tipo. El 13 de ese mes, Harry Truman declaró que conversó con González Videla sobre un corredor para Bolivia, idea que le gustaba (Guzmán, 2015).

El canciller Walker respondió la nota el día 20, en momentos en que la opinión pública de ambos países se mostraba contraria al acuerdo. En Bolivia, el Movimiento Nacionalista Revolucionario (MNR), de Víctor Paz Estenssoro, informó que el gobierno de su país había cedido aguas del Titicaca y una provincia entera a Chile a cambio de un estrecho corredor hacia el Pacífico (Carrasco, 1991). En Chile, Conrado Ríos, negociador del Tratado de 1929, publicó una columna de opinión en Ercilla, recordando que el espíritu del Tratado era contrario a un entendimiento con Bolivia. 
El proceso no tuvo mayores avances. En marzo de 1951, Truman mencionó ante la reunión de cancilleres de la OEA que había un proyecto de desviación de las aguas de los altos lagos ubicados entre Perú y Bolivia, para hacer un "vergel” en la costa occidental de Sudamérica para Perú y Chile, y en compensación dar a Bolivia un puerto marítimo en el Pacífico (Guzmán, 2015). González Videla, desde Santiago, defendió el proyecto. El gobernante peruano Manuel Odría señaló que Perú no había sido informado de ninguna gestión sobre la salida al mar de Bolivia, por lo que la declaración de Truman y de González Videla solo eran “opiniones personales”. Recordó que la frontera entre Chile y Perú fue determinada por el Tratado de 1929, por lo tanto, solo podía modificarse con la participación y asentimiento del Perú. Finalmente, señaló que las aguas del lago Titicaca pertenecen en condominio indivisible a Perú y Bolivia, por lo que este último país no puede negociar sin considerar a Perú. Perú jugó un papel decisivo defendiendo sus derechos residuales sobre Arica, aunque en Bolivia no se quiso valorar la importancia del Perú en el proceso.

El tema marítimo perdió importancia para la política interna boliviana con la revolución del MNR en 1952 (Escobari, 1979). Paz Estenssoro escribió una carta a Hernán Siles, en la que indica:

el problema portuario no figura entre los de primera fila que confronta Bolivia. La afirmación que a menudo se hace de que nuestro atraso proviene principalmente de la falta de una salida al mar, a más de pueril, es tendenciosa, pues busca desviar la atención pública de las verdaderas causas del estancamiento de Bolivia. (citado en Andaluz, 2002, pp. 202-203)

Para el MNR, el asunto del mar no era prioritario (Guzmán, 2015).

A pesar del fracaso del intercambio de notas, la diplomacia boliviana se anotó un importante triunfo al desnaturalizar el espíritu del Tratado de 1929. Si en 1929, la diplomacia chilena entendía que existía una alianza con Perú para que ninguno de ellos aceptara propuestas bolivianas sobre Arica, en 1950, se asumió que se podía conversar directamente con La Paz sin coordinar una política común con Perú. De esta forma, se empezó a erosionar el espíritu del Tratado de 1929.

\section{Charaña: una victoria pírrica}

Tras el fracaso del proceso diplomático de 1950, se abrió otro conflicto entre Chile y Bolivia por el uso de las aguas del río Lauca. De acuerdo con 
un estudio de la International Union for Conservation of Nature and Natural Resources et al. (2006), las primeras protestas bolivianas se realizaron en 1939, luego de que el presidente de Chile, Pedro Aguirre Cerda, anunciara que se canalizarían las aguas del Lauca para irrigar el valle de Azapa. Bolivia guardó silencio hasta 1947, año en que se acordó la constitución de una comisión mixta chileno-boliviana para resolver el asunto. En 1949, la comisión realizó una propuesta sin que las partes presentaran observaciones. En 1954, Chile sostuvo que Bolivia no había presentado observaciones y, en 1958, Bolivia indicó que el acuerdo no era satisfactorio. En 1960, Bolivia llevó el asunto a la OEA, acusando a Chile de un acto de agresión, que amenazaba la paz en América. En 1962, se rompieron las relaciones diplomáticas².

La situación cambió con el quiebre institucional chileno del 11 de septiembre de 1973, pues el gobernante boliviano, Hugo Banzer, fue uno de los pocos mandatarios que apoyó abiertamente la acción de las Fuerzas Armadas chilenas (Bustos, 2004). El general Augusto Pinochet consideró a Banzer como un aliado potencial en un contexto vecinal complejo, en el que se advertían hipótesis de conflicto bélico con Argentina y Perú (Quitral, 2010).

El 15 de marzo de 1974, en la ceremonia de trasmisión del mando presidencial en Brasil, Banzer y Pinochet se reunieron y discutieron el tema marítimo, abriendo un proceso de conversaciones. El 29 de marzo, Juan Velasco Alvarado declaró que Perú jamás aceptaría que Chile le diera un puerto a Bolivia por un territorio que fue peruano. A finales de 1974, se realizó en Santiago una reunión de los subsecretarios de Relaciones Exteriores, en la que se trató la cantidad de petróleo que se enviaba de Oruro a Arica, el asunto marítimo, y se acordó continuar con las negociaciones en febrero de 1975 en La Paz. A finales de enero de 1975, Pinochet invitó a Banzer para continuar las tratativas, en uno de los puntos por donde pasa el Ferrocarril Arica - La Paz: la localidad fronteriza de Charaña. Banzer consultó con su alto mando, aceptó la invitación e instruyó a su canciller de elaborar un proyecto de declaración conjunta.

El 8 de febrero de 1975, Banzer y Pinochet se reunieron y suscribieron el Acta de Charaña. Un instrumento presidencial que "a iniciativa de S.E. el Presidente de la República de Chile, General Augusto Pinochet Ugarte”, disponía que se continuara conversando a distintos niveles "para buscar fórmulas de

2 Este conflicto volvió a la agenda bilateral en 2017, desde que el presidente Morales anunciara que contrademandaría a Chile por las aguas del río Lauca, a propósito de la demanda chilena ante la CIJ sobre las aguas del río Siloli o Silala (Radio Bíobío, 2016). 
solución a los asuntos vitales que ambos países confrontan, como el relativo a la situación de mediterraneidad que afecta a Bolivia”. Banzer consiguió lo que ningún otro boliviano había conseguido hasta el momento ni conseguiría después, un documento oficial, firmado por un gobernante chileno que se comprometía a realizar una negociación sobre su salida al mar.

El restablecimiento de las relaciones diplomáticas no fue bien acogido por la opinión pública boliviana, pues se entendió que reanudar relaciones diplomáticas con Chile era una señal de debilidad. Se afirmó que solo podían restablecerse las relaciones si se conseguía que Chile atendiera de forma efectiva la demanda boliviana (Andaluz, 2002), sin considerar que la falta de relaciones diplomáticas constituye una pauta de normalidad en la relación chileno-boliviana.

El proceso continuó con ofrecimientos impensados para Bolivia. El 9 de junio, el vicealmirante Carvajal, ministro de Relaciones Exteriores de Chile, ofreció al embajador boliviano en Santiago una zona autónoma dentro del puerto de Arica. Aún no estaba zanjado el tema del corredor, y Carvajal proponía este acuerdo que se complementaría con el "compromiso de buscar soluciones al problema específico de un acceso soberano al océano Pacífico conectado con el territorio nacional, dentro de un plazo razonable”. La diplomacia boliviana rechazó la propuesta, acusando que Chile pretendía contentarlos con menos de lo que esperaban, pues sólo ofrecía un enclave en Arica (Guzmán, 2015).

A principios de agosto, el general Sergio Arellano Stark coincidió con el primer ministro peruano (y en cuestión de días, presidente) Francisco Morales Bermúdez, en las celebraciones del sesquicentenario de la independencia boliviana en La Paz, ocasión en la que Morales Bermúdez señaló que no estaba dispuesto a una revisión del Tratado de 1929, en caso de una cesión de un corredor al norte de Arica (Carrasco, 1990). Arellano insistió en que solo se trataba de una hipótesis.

El 28 de agosto, la Junta de Gobierno chilena discutió sobre el Acuerdo de Charaña. Cuando se trató el asunto del "previo acuerdo" que exigía el protocolo complementario, Pinochet indicó que la consulta debería hacerla Bolivia directamente al Perú, sin la intervención de Chile (Junta Nacional de Gobierno, 1975). En La Paz se entendió lo mismo, por este motivo se encomendó a Javier Murillo que se entrevistara con el canciller peruano, Miguel Ángel de la Flor, para entregarle la propuesta específica que Bolivia haría a Chile, y dar cumplimiento al artículo $1 .^{\circ}$ del Protocolo Complementario. La reunión quedó 
en nada, ya que, a los pocos minutos del encuentro, de la Flor abandonó la reunión, pues el primer ministro Morales Bermúdez dirigía una sublevación en contra de Velasco Alvarado, que terminó con su derrocamiento.

La llegada de Morales Bermúdez a la presidencia del gobierno calmó la tensión entre Chile y Perú, y ralentizó las conversaciones chileno-bolivianas. Recién a mediados de diciembre de ese año, Chile envió la “consulta” al Perú, la que fue respondida el 31 de diciembre, con la petición peruana de conocer los documentos del proceso antes de una respuesta, la que Perú demoró. Entremedio hubo negociaciones entre Torre Tagle y el Ministerio de Relaciones Exteriores de Chile para tratar el tema boliviano, y fue a finales de 1976, que apenas Perú entregó una contrapropuesta: un corredor para Bolivia desde la línea de la Concordia al sur hasta la carretera Panamericana; desde la Panamericana hacia la costa, una zona desde la línea de la Concordia hasta el casco norte de Arica. Esta zona sería trinacional, junto con la administración del Puerto de Arica, y en esa zona Bolivia podría construir un puerto, y tener el mar adyacente como territorial (obteniendo más costa que la que ofrecía Pinochet).

El general Pinochet rechazó esa propuesta en noviembre de 1976. En Bolivia hubo una actitud ambivalente, y también demora en las decisiones, pues Banzer rompió relaciones diplomáticas en marzo de 1978 por problemas internos. Pidió que no hubiera compensaciones territoriales, a lo que Pinochet respondió que el canje era condición sine qua non de la negociación.

Las negociaciones fracasaron, pues Bolivia cometió importantes errores, como el diagnóstico. De acuerdo con Maira \& Murillo (2004) se creía en la omnipotencia de Pinochet, sin considerar que el almirante Merino era un contrapeso poderosísimo en la Junta de Gobierno. Otro error estuvo en no concebir la fuerza del sentimiento antichileno en Bolivia, pues la opinión pública de Bolivia no era partidaria de una compensación hacia Chile, que pedía la devolución de su cualidad perdida y una indemnización por los territorios que habían sido ganados en la guerra. La oposición a Banzer quería el fracaso de las negociaciones para evitar que se eternizara en el poder (Andaluz, 2002).

La diplomacia boliviana consiguió una cuña en el espíritu del Tratado de 1929. Consiguió negociar directamente con Chile sobre su pretensión marítima, y llegó a solicitar el acuerdo del Perú, pero fue una victoria pírrica, pues no consiguió la venia peruana, y, por lo tanto, tampoco una salida al mar. 
En Perú, aparecieron alternativas para no volver a estar envueltos en una situación similar. En medio de estas negociaciones, el vicealmirante Guillermo Faura, publicó el libro El mar peruano y sus límites (1977), en el que el corredor boliviano está íntimamente ligado a la definición de los límites del mar peruano, y que en caso de que se cediera "Bolivia pasaría a ser de un país mediterráneo, a un país marítimo enclaustrado entre dos mares: el mar peruano y el mar chileno" (pp. 198-199).

Esta obra fue el inicio de la tesis peruana de la inexistencia de un tratado específico de límites marítimos (Flores Díaz, 2020a y 2020b), y la que utilizó el embajador Bákula para redactar su libro El dominio marítimo del Perú (1985), para iniciar sus trabajos sobre el tema, y para redactar su célebre memorándum de 1986, que inició el proceso de delimitación marítima entre Chile y Perú. Este memorándum se presentó en medio del proceso impulsado por Bolivia, conocido como enfoque fresco.

\section{A modo de conclusión}

La aspiración marítima boliviana es uno de los orígenes de las demandas de Perú y Bolivia contra Chile. Estos pleitos son costosos y limitan la capacidad de los actores involucrados de solucionar por sí mismos estas diferencias, dejándolos en manos de la industria del derecho internacional (Correa \& García, 2016).

El diplomático peruano, Alberto Ulloa, indicó que, en virtud del Protocolo Complementario al Tratado de 1929, Chile y Perú deben actuar en conjunto respecto a la solución de la mediterraneidad boliviana, sin que la política peruana hacia Bolivia sea conducida por Chile. Bákula (2002) señala que los momentos de mayor tensión entre Chile y Perú suceden cuando Chile avanza en conversaciones que implican las cesiones territoriales de territorios, en otro momento peruanos, a Bolivia. Luego del Tratado de 1929, el "factor determinante" de las relaciones peruano-bolivianas fue el interés de Bolivia por solucionar su mediterraneidad, un eufemismo para hablar del interés por Arica.

En Octubre de 2018, la Corte Internacional de Justicia en La Haya desestimó la demanda boliviana en contra de Chile para obligarlo a negociar la cesión de un acceso soberano al mar. Este fallo consideró que una eventual cesión de territorios solo puede producirse mediante un acuerdo libre, en un contexto de excelentes relaciones vecinales (incluido el restablecimiento de relaciones 
diplomáticas). Si se añade el espíritu del Tratado de 1929, la solución al problema boliviano debe ser una iniciativa conjunta entre Chile y Perú. En este sentido, el orden de los factores sí altera el resultado pues la estipulación "sin previo acuerdo entre ellos”, indica que la negociación debe nacer de consuno entre Chile y Perú. Alterar este orden conllevará a repetir una larga historia de acuerdos frustrados.

\section{Referencias}

Agüero, M. (2001). Consideraciones para la delimitación marítima del Perú. Lima, : Fondo Editorial del Congreso del Perú.

Andaluz, H. (2002). Bases jurídicas para la reintegración marítima de Bolivia. La regla pacta sunt servanda como punto cero. Santa Cruz: Editorial Universidad Privada de Santa Cruz de la Sierra.

Bákula, J. M. (1985). El dominio marítimo del Perú. Lima: Fundación M. J. Bustamante de la Fuente.

Bákula, J. M. (2002). Perú: entre la realidad y la utopía. 180 años de política exterior. Ciudad de México: Fondo de Cultura Económica.

Bákula, J. M. (2007). El Perú en el reino de lo ajeno. Historia interna de la acción externa. Lima: Fondo Editorial Universidad de Lima.

Basadre, J. (2014). Historia de la República del Perú [1822-1933]. Tomo 1. Lima, : Producciones Cantabria SAC.

Bello, A. (1864). Principios de derecho internacional. Paris: Librería Garnier Hermanos.

Bernal, J. (1938). El Tratado de Lima de 1929. (Memoria de prueba para optar al grado de licenciado en ciencias jurídicas y sociales, Universidad de Chile, Santiago, Chile).

Brockman, R. (2014). Bolivia, Chile, (Perú) y el mar: entre la obsesión y la indiferencia. En S. Molina (Ed.), Cuadrar el círculo: las propuestas de solución al conflicto entre Chile y Bolivia (pp. 79-94). Santiago de Chile:: LOM.

Brownlie, I. (2012). Principles of Public International Law (7 ${ }^{\mathrm{a}}$ ed.). Oxford: Oxford University Press.

Bustos, C. (2004). Chile y Bolivia. Un largo camino de la independencia a Monterrey. Santiago de Chile: RIL Editores.

Carrasco, S. (1990). Historia de las relaciones chileno-bolivianas. Santiago de Chile: Editorial Universitaria.

Correa, L., \& García, V. (2013). Turbulencias desde el mar: Chile y Bolivia. Si Somos Americanos, 13(1), 93-121. https://doi.org/10.4067/s0719-09482013000100005

Cortés, M. (2015). En torno de las conversaciones de 1950: La política hacia Bolivia de Gabriel González Videla. Si Somos Americanos, 15(2), 149-171. https://doi. org/10.4067/s0719-09482015000200007

Denegri, F. (1988). Perú-Bolivia: una etapa histórica de sus complejas relaciones (19191929). In E. Ferrero (Ed.), Relaciones del Perú con los países vecinos (pp. 97-127). Lima: Centro Peruano de Estudios Internacionales.

Eckholt, E. (2012). "Chile-Perú". In M. Artaza, \& C. Ross (Eds.), La política exterior de Chile, 1990-2009. Del aislamiento a la integración global (pp. 637-692). Santiago de Chile: RIL Editores. 
El Universo. (2009, 31 mayo). Evo Morales acusa a Alan García de obstaculizar acuerdo con Chile. Recuperado 29 octubre, 2019, de https://www.eluniverso.com/2009/06/ 01/1/1361/4147765F93E440D18716CB7440EE8CE0.html

Escobari, J. (1979). El derecho al mar. La Paz: Editorial Urquizo.

Espinosa, O. (1965). Bolivia y el mar. Santiago de Chile: Editorial Nascimento.

Estado Plurinacional de Bolivia (2014). El libro del Mar. La Paz, Dirección Estratégica de Reivindicación Marítima - DIREMAR.

Fernández, G. (2014). Bolivia y Chile: callejón con salida. En S. Molina (Ed.), Cuadrar el círculo: las propuestas de solución al conflicto entre Chile y Bolivia (pp. 47-69). Santiago de Chile: LOM.

Fernández, J. J. (2004). Chile y Perú: historia de sus relaciones diplomáticas entre 1879 y 1929. Santiago de Chile: RIL Editores.

Flores Díaz, S. (2020a). La misión del embajador Juan Miguel Bákula en Santiago en mayo de 1986. Revista Tribuna Internacional, 8(16). doi:10.5354/0719-482X.2019.52443

Flores Díaz, S. (2020b). Análisis del Memorándum Bákula: El documento que inició la redelimitación marítima chileno-peruana. Prolegómenos, 23(45), 165-180. https:// doi.org/10.18359/prole.4060

Flores Díaz, S. (2020c). Cultura jurídica y juicios internacionales: una reflexión sobre el "legalismo mágico" chileno ante las demandas de los países vecinos. En S. Carrasco (Ed.), Vigorización del derecho público. XVLIII jornadas chilenas de derecho público. Concepción, Chile 25 y 26 de Octubre de 2018 (pp. 525-546), Santiago de Chile: Librotecnia.

González, S. (2006). Arica y la triple frontera. Integración y conflicto entre Bolivia, Perú y Chile. Iquique: Aríbalo.

González, S. (2008). La llave y el candado. El conflicto entre Perú y Chile por Tacna y Arica (1883-1929). Santiago de Chile: LOM.

Guzmán, A. (2015). Un mar de promesas incumplidas. La Paz: Plural Editores.

International Union for Conservation of Nature and Natural Resources, Aguilar, G., \& Iza, A. (2006). Gobernanza de aguas compartidas: aspectos jurídicos e institucionales. Gland, Suiza: UICN, Oficina Regional Mesoamérica.

Junta Nacional de Gobierno. (1975). Acta Secreta N. ${ }^{\circ} 228$. Recuperado de https://www. bcn.cl/obtienearchivo?id=recursoslegales/10221.3/34413/1/acta228_1975_A.pdf

Lacoste, P., \& Jiménez Cabrera, D. (2016). El enclaustramiento de Bolivia y el factor Argentina. Si Somos Americanos, 16(1), 119-145. https://doi.org/10.4067/s071909482016000100006

Lagos, G. (1981). Historia de las fronteras de Chile. Los tratados de límites con Perú. Santiago de Chile: Editorial Universitaria.

Leguía, A. (s.f.). Mensaje del presidente del Perú, Augusto Bernardino Leguía Salcedo, al Congreso Nacional, el 12 de octubre de 1929, al concluir su periodo de gobierno. Recuperado 1 septiembre, 2019, de http://www.congreso.gob.pe/Docs/ participacion/museo/congreso/files/mensajes/1921-1940/files/mensaje-1929-1. pdf

Mapa de Virreinato del Perú en 1810 [Ilustración]. (2015, 5 diciembre). Recuperado 16 agosto, 2016, de https://dejesusgomez.blogspot.com/2015/12/mapa-delvirreinato-del-peru-en-1810.html

Martens, F. (s.f.). Tratado de derecho internacional. Madrid: Editorial La España Moderna. 
Mercado, E. (1988). Las relaciones actuales del Perú con Chile y Bolivia: algunas reflexiones. En E. Ferrero (Ed.), Relaciones del Perú con los países vecinos (pp. 149166). Lima: Centro Peruano de Estudios Internacionales.

Muñoz Machado (2017). Diccionario panhispánico del español jurídico. Madrid: Santillana.

Novak, F., \& Namihas, S. (2013). Las relaciones entre el Perú y Bolivia (1826-2013). Lima: Konrad Adenauer Stiftung.

O'Leary, S. (1879). Memorias del General O'Leary. Tomo I. Correspondencia de hombres notables con el Libertador. Caracas: Imprenta de la Gaceta Oficial.

Orias, R. (2004). Bolivia-Chile: La cuestión de la mediterraneidad. Algunas consideraciones desde el derecho internacional. Revista Fuerzas Armadas y Sociedad, 18(1-2), 51-73.

Ostria, A. (1998). Apuntaciones sobre negociaciones portuarias con chile. La Paz, : Archivo y Biblioteca Nacionales de Bolivia.

Parry, C. (2008). Derecho de los tratados. En M. Sorensen (Ed.), Manual de derecho internacional público (pp. 199-259). Ciudad de México: Fondo de Cultura Económica.

Pinochet de la Barra, O. (1987). ¿Puerto para Bolivia? Centenaria negociación. Santiago de Chile: Editorial Salesiana.

Porras, R. (1930). Historia de los límites del Perú. Lima: Librería Científica y Casa Editorial F. y E Rosay.

Quiroga, M., \& Guerrero, N. (2016). ¿Qué se esconde tras La Haya?: análisis de los discursos presidenciales y cobertura mediática en los conflictos Chile-Perú / ChileBolivia. Si Somos Americanos, 16(1), 147-180. https://doi.org/10.4067/s071909482016000100007

Quitral, M. (2010). Chile y Bolivia: entre el abrazo de Charaña y sus relaciones económicas, 1975 - 1990. Universum (Talca), 25(2), 139-169. https://doi.org/10.4067/s071823762010000200009

Radio Bíobío. (2016, 18 julio). Evo Morales denuncia a Chile: "Se verifica el desvío del río Lauca por obras civiles" [Comunicado de prensa]. Recuperado 22 febrero, 2018, de https://www.biobiochile.cl/noticias/internacional/america-latina/2016/07/18/evomorales-denuncia-a-chile-se-verifico-el-desvio-del-rio-lauca-por-obras-civiles. shtml

Ríos, C. (1959). Chile y Perú. Los pactos de 1929. Santiago de Chile: Nascimento.

Ríos, C. (1963). Chile y Bolivia definen sus fronteras, 1842-1904. Santiago de Chile: Editorial Andrés Bello.

Téllez, E. (1989). Historia general de la frontera de Chile con Perú y Bolivia 1825 - 1929. Santiago de Chile: Editorial Universitaria.

Ulloa, A. (1941). Posición internacional del Perú. Lima: Imprenta Torres Aguirre.

Ulloa, A. (1987). Para la historia internacional y diplomática del Perú: Chile, Lima: Atlántida.

Varas, C. (1922). Tacna y Arica bajo la soberanía chilena. Santiago de Chile: Imprenta de La Nación.

Velázquez, J. C. (2007). El problema de los Estados mediterráneos o sin litoral en el derecho internacional marítimo. Un estudio de caso: el diferendo Bolivia-PerúChile. Anuario Mexicano de Derecho Internacional, VII, 379-420. Recuperado de https://revistas.juridicas.unam.mx/index.php/derecho-internacional/article/ view/205 
Wagner, A. (1961). Los límites del Perú. Lima: Editorial Universitaria.

Ydiaquez, E. (1894). Del mapa elemental de Bolivia [Ilustración]. Recuperado 16 agosto, 2016, de https://brbl-dl.library.yale.edu/vufind/Record/4215426

Zapata, A. (2014). La cuestión boliviana. Argumentos. Revista de Análisis y Crítica, 8(1), 19-23. Recuperado de https://revistaargumentos.iep.org.pe/wp-content/ uploads/2014/07/zapata_marzo14.pdf 